\title{
Developing epistemologically diverse learning frameworks
}

\section{Louis Royce Botha}

Division of Studies in Education, Wits School of Education, University of the Witwatersrand, Johannesburg, South Africa

louis.botha2@wits.ac.za

(Received: 05 October 2017; accepted: 20 August 2018)

\section{Abstract}

Education in South Africa is referred to regularly as being in crisis, with learners and educators struggling with various local and international assessments. This state of affairs persists despite considerable efforts having been made to reform and revise the national education system. I contend that these efforts will meet with limited success for as long as schooling continues to be grounded exclusively on the current dominant epistemological bases. I argue for the need to diversify the epistemological foundations of educational systems in South Africa and in Africa in general and offer a strategy for pursuing such aims. I suggest that the notion of an historical epistemology together with expansive learning and cultural-historical activity theory (CHAT) may offer useful conceptual and methodological tools for developing a counterhegemonic epistemological framework in the form of a networked-relational model of learning.

\section{Introduction}

I argue that a significant source of the poor educational achievement of the majority of South African learners can be traced to their alienation from the ontological and epistemological foundations of the country's curricula. More precisely, the majority of South Africa's learners come from black African sociocultural backgrounds where, as Thabede (2014) has insisted, African, or indigenous worldviews and practices endure despite the dynamism of culture and the diversity of people's life experiences. Yet, national educational institutions continue to be organised almost exclusively around what can be considered Western ${ }^{1}$ ontological and epistemological assumptions, resulting in a problematic relationship between these divergent epistemic communities.

\footnotetext{
$1 \quad$ Le Grange and Aikenhead (2016) express concisely the interpretation of the concept of Western that governs this
} article. 
It is well known, for example, that the worldviews of indigenous people differ in significant ways from those immersed in the dominant Western culture and, hence, so does their treatment of knowledge. Referring to African worldviews, Carroll (2014) outlined these differences.

Distinctions between African and European ontologies are based upon an African ontology that posits that the nature of being/reality is fundamentally spirit with material manifestations, and a European ontology which suggests that reality is only material (Ani, 1980; Kambon, 1992, 1996, 1998; Myers, 1987, 1991). Distinctions between African and European axiologies are based upon an African axiology that places the highest prioritization upon interpersonal relationships among people and the collective group, and for the European axiology the highest prioritization is on acquisition of objects and individual gain (Kambon, 1992, 1996, 1998; Myers, 1987, 1991). (p. 259)

These distinctions have implications for how indigenous people, in this case African indigenous people, value and respond to events and experiences and generally relate to social reality (Carroll, 2014). For our purposes here, I want to emphasise the relational aspect of knowledge-making as pointed out, for example, by Fyre Jean Graveline (1998), who stated that we learn in relationship to others, so knowing is a process of "self-in-relation" (as cited in Kovach, 2009, p. 14). Her sentiments about the central role of relationships in the process of knowing are echoed by Mawere (2015) who has asserted that "traditional education placed great importance on interpersonal relationships and reciprocal obligations" (p. 66). Such considerations are not incorporated into transformations of educational institutions on the African continent, and South Africa is no exception. As Kaya and Seleti (2014) have reminded us, instead of nurturing locally and culturally relevant relationships, African educational institutions and their graduates tend to foster ties that perpetuate the disempowering social, economic, and epistemological relations initiated by colonial and imperial conquest.

Elsewhere, I have used Maurial's (1999) conceptualisation of a "continuum between conflict and dialogue" (cited in Botha, 2014a, p. 152) to describe the indigene-western relationship in the context of South Africa. There I allude to one end of the spectrum as being characterised by the kind of conflict that is illustrated by the colonial conquests of indigenous people's lands, bodies, and minds, through a point of assimilationist processes of disindigenisation which involves slave, mission, and Bantu education, among others, to a further point on the spectrum which is more dialogical and which involves the incorporation of indigenous knowledges into Western ones, and vice versa.

These interactions give rise to an essentially dialectical relationship which gives meaning to what can be understood as indigenous (and Western). Hence, Breidlid and Botha (2015) define indigenous primarily in terms of a shared experience of domination "which, for indigenous people, originates with and is perpetuated by their contact with a modern western system of social organization" (p. 321). This particular form of contact, when it takes the 
shape of Western schooling, can be an overwhelmingly negative experience for those, like South Africa's black learners, whose epistemic roots lie in indigenous ontological bases.

Shiza (2013) supported such a view in his observation that the African experience of schooling, or "Europeanized education, in other words, is a means of mystifying knowledge and reality, an alienating and dehumanizing process that continues to this day" (p. 6). In making this argument, Shiza started off by pointing out that school knowledge is an expression of socio-cultural need and development and therefore "should align itself with learners' experiences that are characterized by their socio-cultural worldviews" (p. 5). He then pointed out that schooling on the African continent was initiated by a colonial process that sought to undermine indigenous peoples and their knowledges, and continues to be rooted in, and oriented toward this foreign cultural, ontological, and linguistic experience. Further, Shiza claimed that this colonial education "did more than corrupt the thinking and sensibilities of the Africans; it filled their minds with abnormal complexes, which deAfricanized and alienated them from their socio-cultural milieu" (p. 9).

This perception of the impact of colonial education was shared by Mazrui (1993) who drew on Fanon's work to argue that continual dehumanisation of the colonised through religious and educational processes ultimately results in alienation. Defining alienation as "the separation of individuals from their existential conditions, from their individuality and culture" (p. 355), Mazrui argued that once this alienation is in place, the cultural resources of the colonised become closed off for their development. Thus, education for the colonised Africans becomes a process through which they attempt to access the zone of the coloniser but are denied this and are forced to stay trapped in the zone of the colonised where they are disconnected from and see no value in the cultural resources of the colonised.

The effects of this alienation are evidenced by the numerous reports by researchers such as Stavenhagen (2008) who claimed that "the academic performance of indigenous pupils . . falls far below that of the non-indigenous population." He went on to say that

in Chile, the levels of education attained by the indigenous population are significantly lower than those of the non-indigenous population; twice as many indigenous people lack any formal education at all (6.3\% as compared to $3.1 \%$ ) or have not completed basic education (21.3\% as compared to $10.2 \%)$. (p. 165)

Castagno and Brayboy (2008) showed similar disparities between the academic achievement of American Indian and Alaska Native students and other groups of students in US schools. Similarly Shay (2016) cited a report that indicated that only 53.9 per cent of indigenous Australians aged 20-24 years attained a Year 12 qualification or the equivalent, while Hare and Pidgeon (2011) claimed that "in Canada, the proportion of Aboriginal youth, aged 15 and over, who do not complete high school is 40 per cent, compared with 13 per cent for nonAboriginal young adults" (p. 94). In summary, these authors all indicated that conventional schooling presents an epistemological challenge for indigenous students. 
In line with this, South African learners' academic performance on international comparative tests seems to indicate that the majority of them are not coping with the education that is on offer. The 2015 Trends in International Mathematics and Science Study (TIMSS) which is "an assessment of the mathematics and science knowledge of fourth and eighth grade students around the world" (Reddy et al., 2016, p. 1) showed that the South African learners achieved the second lowest score for mathematics - 372 points - and the lowest for science358 points - compared to Singapore, which achieved the highest scores of 621 and 597 respectively, in these categories. Similarly, Taylor (2009) pointed out that for the Southern and Eastern African Consortium for Monitoring Education Quality (SACMEQ), South Africa performed poorly compared to its neighbours, most of which are more impoverished countries. To this end, Taylor (2009) made the point that material resources do not seem to be the determining factor when it comes to performance on these international tests. Like Long and Wendt (2017), he showed that some of the well-resourced schools in South Africa also struggled in key assessment areas. However, the achievement gap across schools seems to be strongly related to the country's historical racial classifications, "with African schools overwhelmingly represented in the poor performing category" (Taylor, 2009, p. 11).

Interestingly, when Song, Perry, and McConney (2014) compared the Programme for International Student Assessment (PISA) 2009 scores for New Zealand and Australia, they found that although these two countries consistently scored well on the international assessment instrument, their indigenous students did not.

For New Zealand, PISA scores of Māori and Pacifika students are much lower than the average for Päkehä/European students . . . Specifically, students identifying as Päkehä/European (71\% of all students) achieved an average reading score of 541 score points in reading literacy on PISA 2009. In contrast, students identifying as Māori (19\%) and Pacifika (10\%) scored 478 score points and 448 score points, respectively, considerably below the OECD mean.

They also claimed that

for Australian Indigenous students, the picture may be even bleaker . . . Indigenous students lagged behind their non-Indigenous peers by 82 points in reading literacy. This gap equates to more than one PISA proficiency level or more than 2 years of schooling (p. 181).

Bang, Warren, Rosebery, and Medin (2012) cited Cheryl Harris's (1995) concept of "settled expectations" to explain the barriers to learning experienced by students from non-dominant communities. They used her definition of this notion as "the set of assumptions, privileges, and benefits that accompany the status of being white ... that whites have come to expect and rely on across the many contexts of daily life" (Bang et al., 2012, p. 303) to uncover the ways in which the dominant (white) group's values and practices are rewarded by social structures and institutions such as schools. As they put it, 
when applied to schooling, the construct of settled expectations can usefully articulate and problematize entrenched, usually hidden, boundaries that tend to control the borders of acceptable meanings and meaning-making practices. These have also shaped deficit-oriented discourses concerning students from non-dominant communities. (p. 303)

Thus, in relation to schooling, settled expectations give value to what is acceptable in terms of content, explanations, experiences, behaviours, knowledge-making practices, and so forth. Bang et al. (2012) illustrated the operation of this concept through the story of Jonathan, a middle-school learner from a non-dominant community who questioned explanations offered by the conventional science of the curriculum, and by his classmate, both of whom were based in the dominant group. The authors pointed out that "despite the intellectual force of his argument, he ultimately yielded to the normative authority of the curriculum" (p. 305), with his query being dismissed and his European American classmate's explanation valued. The result of this was not only that the dominant paradigm was shown to be incontestable, but also that Jonathan effectively withdrew from engaging with it.

This North American example can be seen to parallel the experiences of black students in an African or South African context when they draw on the kinds of indigenous ontological or axiological assumptions outlined earlier to question the content or expectations of their current curricula about, for instance, how lightning works, how diseases manifest, what constitutes appropriate protocols for debating with an older person, and so forth. Considering Jonathan's response (see Bang et al., 2012), it is worth noting that Sheppard (2015), in his discussion of research on school retention in South Africa, reported that $17 \%$ of African/Black and 30\% of Coloured respondents indicated that their reason for dropping out of school was that "education is useless and uninteresting." None of those in the categories Indian and White, who more readily conform to the "settled expectations" (p. 21) of the South African classroom, cited this reason.

\section{A call for epistemic diversity}

Thus far, I have discussed the concept of indigenous as arising from an experience with a dominating, colonial force that has, in relation to education, produced students who are alienated from their significantly different ontological, epistemological, and axiological foundations, and who therefore experience difficulty negotiating the dominant educational structures. With reference to South Africa as well as other national contexts, I have in this way suggested that the alienation of indigenous students, as members of a non-dominant community, could be a major contributing factor to their poor academic performance at school.

In making this claim, I am not denying the significant correlations found between socioeconomic factors relating to school communities, and teachers' knowledge (Carnoy \& Chisholm, 2008), the role played by a lack of basic amenities, or weak and under-resourced early childhood education (McFarlane, 2011), poor professional practices on the part of 
teachers (Taylor, 2009), or the many factors, from hunger to an inability to pay school fees, that lead to students dropping out (Sheppard, 2015). I am also cognisant of the constraints imposed by dominant international frameworks that Jones (2007) has described, that indicate that "despite the persistence of local uniqueness, education around the world is seen to become increasingly standardized" (p. 331). Even though South Africa may have sought to address fairly unique educational challenges brought about by its colonial and apartheid history, many of its efforts have been compromised by the current transnational structuring of educational systems that are aligned to a dominant Western notion of education that is currently driven by a neoliberal agenda (Biesta, 2009). As Subreenduth (2013) has argued, curricula and social justice policies developed by the post-apartheid government are framed in discourses that "reflect neoliberal globalizing and market-oriented trends more than transformative social justice ideologies" (p. 593). She went on to say that

global, neoliberal social justice discourse on education is clearly linked to the global knowledge economy that prizes market efficiency, standards, and corporate-style accountability. In the case of South Africa, this discourse also clearly undermines the fundamental social justice efforts undertaken to redress apartheid oppression and to rehumanize black South Africans through recentering indigenous knowledge (culture, language, ritual) as a valuable component of the fabric of society. (p. 596)

Fataar (2016), however, has suggested that the failure of policy rests with the unanticipated consequences of its implementation brought about by "the survivalist circumstances of the township" (p. 39). He also cited "the failure of theoretical indigenisation" (p. 40) and the fact that "the sociology of South African education lacks a rigorous account of the educational subject" (p. 41) as two more reasons behind the difficulties faced by the South African education system and, consequently, its learners.

The above perspectives resonate with my position here in its agreement with Fataar's (2016) call for "thinking at the limits of our epistemological frames and our methodological orientations" (p. 41) by proposing a re-modeling of our ideas about knowledge-creation, especially in predominantly non-western contexts. Letseka (2014), too, has called for a complete redesign or re-engineering of the system. As she has said, "Presumed in the discourse of 'redesigning' and 'reengineering' is a radical shift from outdated modes of thinking to a completely new, often uncertain ways of doing work" (p. 4867). Such a shift is appropriate for current developments in the world of work where notions of learning and expertise are being reconceptualised (Engeström, 2004) as the boundaries between microand macro-level processes, and mental and material resources become increasingly blurred. However, it also resonates with calls for a more socially just education.

Recently, in South Africa, demands for social justice have included louder calls for the decolonising of institutions of higher learning by student protest movements such as \#RhodesMustFall and \#FeesMustFall. While such transformative processes may have, to some extent, already begun in the form of initiatives such as the IKS Programme at North- 
West university $^{2}$ (see, for example, Kaya \& Seleti, 2014), they seem to be confined to institutions of tertiary education. While curriculum changes and policy initiatives abound, there have not been similar government-led or civic-led endeavours for addressing the apparent contradictions that lie at the root of South African learners' difficulties with accessing knowledge-making in their schools.

In attempting to address this issue, I have drawn on a sociocultural approach to learning and human development in general. Rogoff (2003) has explained the way in which learning is seen from this perspective.

Cognitive development consists of individuals changing their ways of understanding, perceiving, noticing, thinking, remembering, classifying, reflecting, problem setting and solving, planning, and so on - in shared endeavors with other people building on the cultural practices and traditions of communities. Cognitive development is an aspect of the transformation of people's participation in sociocultural activities. (p. 237)

Socioculturalists, therefore, view learning as an activity that is shaped by participation in a cultural community; its beliefs, knowledges, values, and practices, shape and take shape around historically developing artifacts. As Rogoff put it, "Individuals and social groups build on connections made for them by previous generations, often mediated by cultural tools that they inherit" (p. 258) The earlier description of the development of schooling in an African (colonial) context demonstrates clearly that the culturally mediated activity of schooling has not followed such an historical process for the indigenous people. It is not surprising, therefore, that members of some communities will not engage with schooling and the knowledges it favours since this is discrepant with what is seen to be culturally necessary.

Rogoff (2003) demonstrated this by referring to how various communities understand learning and intelligence differently. She points to Ugandan villagers who "associated intelligence with adjectives such as slow, careful, and active," while for Mexican Americans educado includes "a sense of moral and personal responsibility and respect for the dignity of others that serves as a foundation for all other learning" (p. 249). Similarly, nzelu is a Zambian concept of intelligence that implies its use in a socially productive way only, while for the Baoule` of Ivory Coast $o$ ti kpa is intelligent behaviour that impacts positively on the family's well-being. These notions do not readily resonate with what is prioritised in South African schools and the kinds of assessments mentioned earlier. This implies that introducing different tools and values into the education system might be useful.

The sociocultural approach to understanding learning and development as participation in a social activity, and cultural-historical activity theory (CHAT), expansive learning in particular, offer useful conceptual and methodological tools for developing a new model of knowledge-making in educational institutions. I envision this project as being guided by the

According to Kaya and Seleti (2014) this programme is one which brings local languages, community practices, content and practitioners into the teaching and research of the university, and is the only accredited higher education programme for indigenous knowledge on the African continent. 
principles offered by expansive learning and CHAT analyses that include the historicisation and harnessing of the tensions inherent in bringing diverse ontologies and epistemologies together. The model proposes that the technicist market-oriented approaches that frame current educational policies and curricula be brought into dialogue with more inclusive, indigenous perspectives. Moreover, I will show that the model is intended to instigate the epistemological change it represents.

\section{Modelling future epistemologies with CHAT}

As mentioned above, the analytical framework for my proposed project of epistemological diversification in education is that of cultural-historical activity theory (CHAT) together with expansive learning. While this complex theoretical framework cannot be elaborated upon here, elsewhere (Botha 2014b), I have summarised it as follows:

CHAT has developed from Lev Vygotsky's attempts to account for socially mediated learning and offers an analytical framework that investigates human activity as a system of individual, communal and societal relationships which are historically developing and mediated by tools, rules and the division of labour.

In addition to offering an analytical system of relations that are artifact-mediated and historically situated (see for example Engeström, 1987; Engeström \& Glăveanu, 2012; Kaptelinin \& Nardi, 2006) other key aspects include understanding human activity as objectoriented, that is, activities such as learning are driven by objectives; and harnessing contradictions as opportunities for change and development (Engeström, 2001). Although these and other CHAT principles are clearly relevant for an agenda of epistemological change (see, for example, Botha, 2012), they will be alluded to only briefly since their operation is not what I want to demonstrate here. Instead, what I want to put forward is the process whereby the model itself becomes a tool for transformation, and for this purpose the process of expansive learning is key.

Thus, in applying CHAT and expansive learning I am proposing that the key to effective, systemic change lies beyond the development of the analytical model, and more toward an emphasis on the promotion of the model. The success of radical new forms of learning, such as those based upon the kind of indigenous African epistemologies and philosophical principles mentioned above, is primarily connected to the successful modelling of these forms of learning, starting with the process of expansive learning. Expansive learning, as Engeström (2001) explains, develops Gregory Bateson's (1972) theory of learning into a systematic framework in which the conditioning that comprises Learning I and learning of rules and patterns that characterises Learning II, can give rise to conflicting impulses leading to Learning III, where the situation is called into question. Consider the following explanation, bearing in mind the problem that I am addressing in this article.

Thus, in classrooms, students learn the 'hidden curriculum' of what it means to be a student: how to please the teachers, how to pass exams, how to belong to groups, etc. Sometimes the context bombards participants with contradictory demands: Learning 
II creates as double bind. Such pressures can lead to Learning III where a person or a group begins to radically question the sense and meaning of the context and to construct a wider alternative context. Learning III is essentially a collective endeavour. (Engeström, 2001, p. 138)

Expansive learning, therefore, is the process of resolving contradictions in an activity system, so that new forms of activity emerge (Engeström, 2007). I am suggesting that, for learners from non-dominant, indigenous communities, learning in schools constitutes an activity fraught with conflicting impulses as they try to assimilate, appropriate, reject, and experience rejection through their historically dominating schooling. Through expansive learning the object, tools, and organization of activities in the school activity system could take on broader new forms, and, in the process, also transform the subject (Engeström \& Sannino, 2016). This process of imbuing the subject with transformative agency can be explained by Vygotsky's principle of double stimulation: the first stimulus provides a problematic situation characterized by contradictions, and the second stimulus provides the tool that propels the attempted resolution of the contradiction. Elaborating on the operation of double stimulation, Engeström and Sannino outline several stages, including Apparatus 1, a four phase process of formulating a response to a conflictual situation, and Apparatus 2, implementing the response. The authors refer to Vygotsky's "experiment of the meaningless situation" (as cited in Engeström \& Sannino, 2016, pp. 404-406), during which the experimenter leaves a participant in a room without any instructions thus creating a situation of conflicting motives to do with whether to leave or stay. Typically, the participant uses the clock on the wall to set a deadline for when to leave. "The clock functions as a second stimulus . . . it becomes a sign that enhances the will of the subject and allows breaking out of the paralyzing situation" (p. 404).

This process explains the mechanism by which I think the proposed model of relational knowing could be adopted. The generative principle of double stimulation offers a theoretical insight into how the impetus for transformative agency could develop among learners from non-dominant communities, allowing them to break free of the alienating situation imposed by the culturally foreign activity of schooling. In this case, the networked relational model of learning, which I outline below, becomes the second stimulus that prompts the volitional actions that lead to the development of new forms of learning in schools. An illustration of this process was offered by Engeström and Sannino (2016) through an example from a research intervention with a farming community in Ethiopia. They explain how a threedimensional community map produced by the villagers instigated their recognition that the problems of poor soil, failing crops, and hunger could be traced to the recent destruction of the nearby forest. At the same time the map also spurred them to take action, as the clock did for the participants in the meaningless situation.

... it was a representational device that allowed the villagers to expand their vision beyond the here-and-now, both in space and in time, and to start building a model for the future. Such a model will itself turn into a new second stimulus in a long chain of actions of transformative agency (Engeström \& Sannino, 2016, p. 408). 
I believe that non-dominant communities could be inspired to make similar conceptual leaps about the current and possible future forms their education could take, if confronted with a relational model of learning that reflects familiar indigenous epistemological principles.

In this regard Wartofsky's (1979) concept of an historical epistemology offered some further insight. Consider, for example, his view that "the cognitive artifacts we create are models: representation to ourselves of what we do, of what we want, and of what we hope for. The model is not, therefore, simply a reflection or a copy of some state of affairs, but beyond this, a putative mode of action, a representation of prospective practice, of acquired modes of action" (p. xv). The idea is that the model shapes the activity of the system, becoming something of a template around which the expanded learning develops. This idea of a model that shapes activity is not foreign to Vygotsky and to activity theory. One could, for example, point to Sannino and Sutter's (2011) explanation of how Vygotsky advocated the use of the indirect method, to suggest that a similar idea of a Das Kapital for learning is needed to develop new forms of knowledge-making. Such a revolutionary theoretical treatise could use the conceptual framework of CHAT to interrogate dominant epistemological models and instigate the formation of new ones. In doing so it would produce a clear representation of exactly what the new activity system of alternative epistemologies would look like, a complex task that can only be hinted at here. The purpose of the model would then be to instigate the development of ideas and practices that conform to the character of the model and eventually realize its principles, as described above by the double stimulation process.

To this end I am proposing a networked relational model of learning, one that focuses on relationships as a key component of its epistemology. The prioritisation of relationships in learning and development is based on the earlier identification of the primacy of relationships in indigenous people's knowledge-making. It further represents a desettling of dominant constructions of how such learning and development happens. For example, for the teaching of science, Bang et al., (2012) have suggested the need to move away from human centred, hierarchical and atomised understandings of nature, "toward relational frames in which humans are part of thickly networked, multiple storied "hives of activity"' (p. 315). Taking a CHAT approach to education more generally, Edwards (2017) has stated that "the starting point is the premise that pedagogy, i.e., teaching to enhance learning, is a relational and therefore responsive activity" (p. 556). She goes on to explain the dialectical relationship between the learner and practice, arguing that this externalisation-internalisation relationship shapes the various elements of the activity system; motives, tools, practices, and so forth shape each other through historically mediating processes.

The networked relational model of learning seeks to bring to the fore this fundamental epistemological principal of knowing as relational by identifying the making of connections between its nodes as the primary means by which knowledge is constructed and held, thereby also drawing attention to its networked structure as a representation of knowing.

In order to put into effect such a model, relevant artifacts and actors have to be identified and connected into a network in ways that prioritise the desired processes, values, and outcomes that are to characterise the new forms of learning. Here I propose a careful examination of 
indigenous and other marginalised knowledge-making systems in order to identify the who, what, where, and why of their functioning. The networked model would then be developed by carefully mapping out the relative positions of the actors and the material and conceptual tools that comprise the alternative knowledge-making activity system so that they appear as a network of relationships that represent the ways in which the artifacts, subjects, rules, community, and division of labour are connected in pursuit of their object (objective) of creating the desired (relational) knowledge and practices. The patterns of connections could then be analysed in terms of a social network perspective (Phelps, Heidl, \& Wadhwa, 2012; Tichy, Tushman, \& Fombrun, 1979) framed by cultural-historical activity theory, so that appropriate resources may be introduced in ways that enhance their collective potential for achieving the desired change.

Such a networked relational approach focuses, first, on the meditational tools, or artifacts, that comprise the knowledge-making activity systems. It assumes that the cultural artifacts of an activity determine fundamentally the ways in which it is performed, regardless of the nature of the knowledge that the activity is developing. Representing these resources as nodes in a network makes it possible to locate them and identify the potential of their roles in terms of the arrangement within the activity, that is, the network's structural properties.

Furthermore it is reasoned that the nature of the activity and its outcomes can be influenced by introducing, modifying, and/or rearranging tools and other resources that mediate the activity. From an activity theory perspective, identifying the meditating role of persons or instruments would involve a thorough investigation of how they are historicised within the rules, community, and division of labour of the activity.

This implies a second, related aspect to facilitating the co-construction of mutually beneficial development and research activities that focus on the nature of the links between actors and other resources in the network. Qualifying these connections in terms of their proximity, intensity, durability, and so forth offers different possibilities for understanding and influencing the shape of the model, and therefore the nature of the practices and knowledge that it produces. I offer a basic outline of the modelling process here.

The first step is to construct a model of knowledge-making that conveys its key principles in a way that captures the imagination. In this case, because the intention is to emphasise the relational nature of knowledge construction, I want to evoke the image of a neural network and depict the connections between and among various actors, tools, and rules as being like neurons in the brain. The new model would then present learning as a network of relationships in the activity system. Its brain-like appearance, as indicated by Figure 1, below, would facilitate the acceptance of the desired alternative perception and enactment of knowledge as being constructed and held within connections, or relationships. 

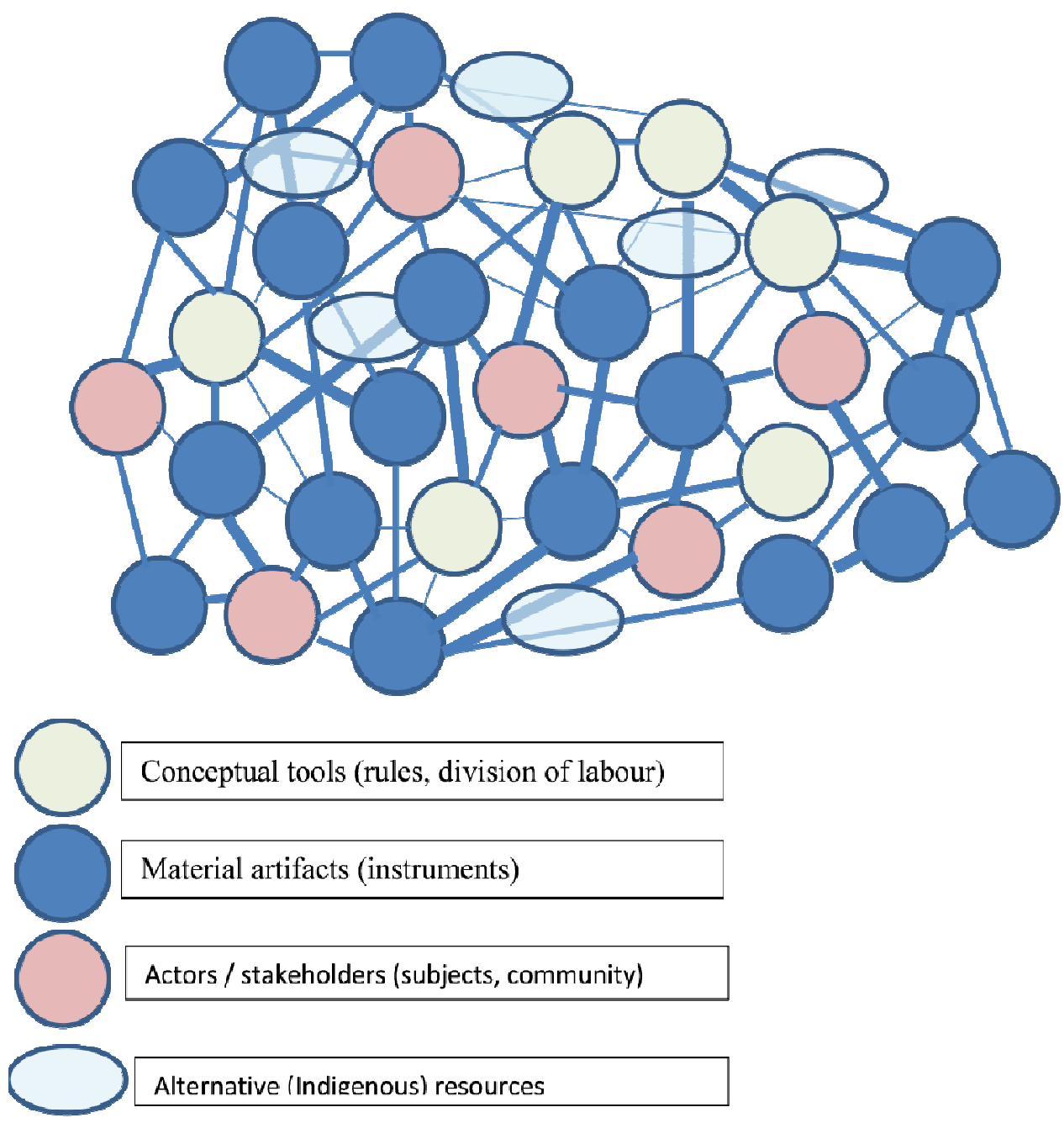

Figure 1. A Model of knowledge as a network of relationships

The second step of the model making process involves identifying all the possible contradictions that may arise as a result of implementing the new model. These contradictions are testimony to the fact that the project is situated in contexts that are fundamentally shaped by the dominant epistemology. From a CHAT perspective the contradictions occur at four levels: primary level contradiction that entails systemic tensions between the use, value, and exchange value of the system's tools, rules, and division of labor; secondary level contradictions occur between nodes in an activity system; tertiary contradictions arise when an object from a more "culturally advanced" activity is introduced; and quaternary level contradictions involve neighbouring activities (Foot \& Groleau, 2011). As indicated above, such contradictions would stem from the incompatible philosophical assumptions that form the bases of predominantly Western hegemonic models of learning, on the one hand, and counterhegemonic epistemologies such as those of African and other indigenous communities on the other. Included among these contradictions would be diverging ideas about what constitutes knowledge, logic, and rationality, who can access and produce knowledge, and why we need to know at all. Currently, in the South African educational contexts these contradictions would be related to some of the factors alluded to earlier, such as the neoliberal agenda driving educational reform, politically motivated policy changes, 
inappropriately theorized and implemented interventions, and so forth. What I therefore suggest is that we make use of CHAT to expose the roots of these contradictions in terms of the divergent activity systems of knowledge-making by which many African and other learners from indigenous communities are expected to operate.

A third related step in developing the model for empowering marginalized epistemologies entails introducing actions and artifacts into the system that promote the development of the envisioned epistemological model. Thus, one would systematically identify the relationships between and among the various actors and resources that are instrumental to the ways in which the new process of knowledge-making should work. We need, therefore, to ask which types of people, instruments, documents, institutions, spaces, ideas and so forth are valued most highly for the construction of the proposed new kind of knowledge. Some of the suggestions indicated above, such as theoretical indigenization (Fataar, 2016) and the desettling of dominant epistemologies (Bang et al., 2012) can be considered in this way by looking at how new groups of stakeholders, policies, concepts, learning spaces, and other resources can be included and empowered within the system.

The alternative (indigenous) resources to be included into a learning network as illustrated in Figure 1, above, could be the kind, indicated by Carroll (2014), that would include material, epistemological or moral resources from indigenous communities. In a similar way to that of scientific communities of practice which operate according to shared norms, values, and practices, a knowledge community based on an indigenous epistemology would proceed from an ontological position that values the connectedness of its actors and artifacts. Such a relational approach to knowledge-making is evident in the indigenous prioritizing of community through approaches like the Te Kotahitanga approach to Maori education (see for example Hynds et al., 2011), confianza in the funds of knowledge approach (González, Moll \& Amanti, 2006) which draws minority communities' knowledge resources into the classroom, or the notion of $U_{b u n t u^{3}}$ originating from African cultural values prioritizing connectedness (le Grange, 2011).

This will inevitably result in further tensions and conflicts as the competing hegemonic and counterhegemonic systems of knowledge-making come into contact with each other. As Engeström (1994) pointed out, "Each action is shaped by, and in turn gives shape to the historically evolving structures and contradictions of the entire activity system, including the not immediately visible factors of communities, institutional rules, and division of labour" (p. 410).

Consequently, I propose that the fourth step towards attaining the envisioned epistemological change would be to employ the historical elements of the activity system's responses (development) to harness the contradictions and direct the systemic change. The logic behind this is effectively captured by Engeström (1994) who noted that

These are complex concepts that have been developed by academics who argue that they entail more than what a translation can convey; they defy translation. However, confianza has connotations of trust and Ubuntu is often translated as "I am because we are." 
from an activity theoretical viewpoint, the specific contradictions of any practice should be interpreted against the historical evolution and developmental potential of that particular activity system ... this inclusion of history into the situation can turn contradictions into a resource: they give rise to disturbances and failures, but they also elicit innovative solutions that point toward possibilities of systemic change. (p. 411)

Needless to say, the identification and application of CHAT principles to the construction of the networked/relational model requires a more detailed and specific analysis than is possible to offer here. However, it should be evident from the above that this analytical framework is compatible with the suggested programme of change envisioned here for epistemologically marginalised South African and African communities in general, one in which they can take command of the shape and direction of their learning.

\section{Conclusion}

That the majority of black South Africans are struggling with the national system of education is clear, as should be the fact that good policies and moderate reforms are not enough to alter this situation. This set of affairs, however, is not a uniquely South African, or even African one, but seems to pertain wherever indigenous communities are educated in a system that ignores or undermines their epistemic heritage. While considerable political will and a strategic use of resources are required to change these hegemonic Western systems meaningfully, I have argued here that the key component to appropriately re-engineering them lies with the modelling of alternatives. If we are to achieve the aim of diversifying our knowledge-making, such a vision will not be achieved by its desirability or even its necessity alone, but it will also depend upon its ability to capture the imagination and move it in the desired direction.

Radical educational change must therefore begin with a model that convincingly portrays alternative epistemological processes as effective and that resonates with concepts and values held by influential knowledge-makers from all kinds of backgrounds. It should allow them and persuade them to visualise knowing in particular ways, thereby conditioning discourses and practices around learning, teaching, and other knowledge-making activities. When we picture knowledge-making as producing brain-like neural networks of people, spaces, and artifacts, for example, and when that image resonates with how we understand the shaping of ideas, emotions, and other components of knowing we will adapt our conceptual and other tools, values, and activities so that they reflect and nurture that perception.

Furthermore, a model should be grounded in a strong theoretical framework so that it offers clear pathways for the uptake of new, unconventional, or counterhegemonic ideas. Here I have demonstrated that CHAT is able to provide analytical tools and strategic support for a programme of change like the one proposed for diversifying the epistemological foundations of educational institutions. The way in which it employs contradictions, mediation, and historicity enhance the significance of relationships that make up the networked model, giving further credence to this vision of knowledge-making. 


\section{References}

Bang, M., Warren, B., Rosebery, A. S., \& Medin, D. (2012). Desettling expectations in science education. Human Development, 55(5-6), 302-318.

Bateson, G. (1972). Steps to an ecology of mind. New York, NY: Ballantine Books.

Biesta, G. (2009). Good education in an age of measurement: On the need to reconnect with the question of purpose in education. Educational Assessment, Evaluation and Accountability (formerly: Journal of Personnel Evaluation in Education), 21(1), 3346.

Botha, L. R. (2012). Using expansive learning to include indigenous knowledge. International Journal of Inclusive Education, 16(1), 57-70.

Botha, L. R. (2014a). Liberating education: A dialectical approach to knowledge diversification. Sosiologisk Arbok, 1, 131-57.

Botha, L. (2014b). Taking safety promotion and injury prevention. African Safety Promotion, 12(2), 1-9.

Breidlid, A., \& Botha, L. R. (2015). Indigenous knowledges in education: Anticolonial struggles in a monocultural arena with reference to cases from the global south. In W. Jacob, S. Cheng, \& M. Porter (Eds.), Indigenous Education. Language, Culture and Identity (pp. 319-339) Amsterdam, NL: Springer.

Carnoy, M., \& Chisholm, L. (2008). Towards understanding student academic performance in South Africa: A pilot study of Grade 6 mathematics lessons in Gauteng province. Pretoria, RSA: HSRC.

Carroll, K. K. (2014). An introduction to African-centered sociology: Worldview, epistemology and social theory. Critical Sociology, 40(2), 257-270

Castagno, A. E., \& Brayboy, B. M. J. (2008) Culturally responsive schooling for Indigenous youth: A review of the literature. Review of Educational Research, 78(4), 941-993.

Daniels, H., Edwards, A., Engeström, Y., Gallagher, T., \& Ludvigsen, S. R. (Eds.). (2013) Activity theory in practice: Promoting learning across boundaries and agencies. London, UK: Routledge.

Edwards, A. (2017). Relational expertise: A cultural-historical approach to teacher education. In M. Peters, B. Cowie, \& I. Menter (Eds.), A Companion to research in teacher education (pp. 555-567). Singapore: Springer. 
Engeström, Y. (1987) Learning by expanding: An activity-theoretical approach to developmental research. Helsinki: Orienta-Konsultit. Retrieved from http://lchc.ucsd.edu/MCA/Paper/Engestrom/expanding/toc.htm

Engeström, Y. (1994) Objects, contradictions and collaboration in medical cognition: An activity-theoretical perspective. Artificial Intelligence in Medicine, 7, 395-412.

Engeström, Y. (2001). Expansive learning at work: Toward an activity theoretical reconceptualization. Journal of education and work, 14(1), 133-156.

Engeström, Y. (2004) New forms of learning in co-configuration work. Journal of Workplace Learning, 16(1-2), 11-21.

Engeström, Y. (2007). Enriching the theory of expansive learning: Lessons from journeys toward coconfiguration. Mind, Culture, and Activity, 14(1-2), 23-39.

Engeström, Y., \& Glăveanu, V. (2012) On third generation activity theory: Interview with Yrjö Engeström. Europe's Journal of Psychology, 8(4), 515-518

Engeström, Y., \& Sannino, A. (2016). Expansive learning on the move: Insights from ongoing research/El aprendizaje expansivo en movimiento: Aportaciones de la investigación en curso. Infancia y Aprendizaje, 39(3), 401-435.

Fataar, A. (2016) In search of the elusive educational subject: Priorities for research in the field of education in South Africa today? Faculty of Education Research Bulletin, Stellenbosch University. Retrieved from http://www.sun.ac.za/english/Downloadable\%20Documents/Opvoedkunde/Navorsing sbulletin_edit3.pdf\#page $=40$

Foot, K. \& Groleau, C. (2011) Contradictions, transitions, and materiality in organizing processes: An activity theory perspective. First Monday, 16(6). Retrieved from http://firstmonday.org/ojs/index.php/fm/article/view/3479/2983

González, N., Moll, L. C., \& Amanti, C. (2006) Introduction: Theorising practices. In N. González, L. C. Moll, \& C. Amanti (Eds.), Funds of knowledge: Theorizing practices in households, communities, and classrooms (pp. 1-24). New Jersey, NJ: Lawrence Erlbaum.

Hynds, A., Sleeter, C., Hindle, R., Savage, C., Penetito, W., \& Meyer, L. H. (2011) Te Kotahitanga: A case study of a repositioning approach to teacher professional development for culturally responsive pedagogies. Asia-Pacific Journal of Teacher Education, 39(4), 339-351.

Jones, P. W. (2007) Education and world order. Comparative Education, 43(3), 325-337. 
Kaptelinin, V., \& Nardi, B. A. (2006) Activity theory in a nutshell. In V. Kaptelinin \& B. Nardi (Eds.), Acting with technology: Activity theory and interaction design (pp. 2972). Cambridge, MA: MIT Press.

Kaya, H. O., \& Seleti, Y. N. (2014) African indigenous knowledge systems and relevance of higher education in South Africa. International Education Journal: Comparative Perspectives, 12(1), 30-44.

Kovach, M. (2009). Indigenous methodologies: Characteristics, conversations and contexts. Toronto, Canada: University of Toronto Press.

le Grange, L. (2011) The philosophy of Ubuntu and education in South Africa. In W. Veugelers (Ed.), Education and humanism: Linking autonomy and humanity (pp. 6778). Rotterdam, NL: Sense.

le Grange, L., \& Aikenhead, G. (2016). Rethinking the "Western Tradition": A response to Enslin and Horsthemke. Educational Philosophy and Theory, 49(1), 31-37.

Letseka, M. (2014). The illusion of education in South Africa. Procedia-Social and Behavioral Sciences, 116, 4864-4869.

Long, C., \& Wendt, H. (2017). A comparative investigation of South Africa's highperforming learners on selected TIMSS items comprising multiplicative concepts. African Journal of Research in Mathematics, Science and Technology Education, 21(2), 109-124.

McFarlane, D. (2011, July 01) The damage schools do to children. Mail \& Guardian. Retrieved from http://mg.co.za/article/2011-07-01-the-damage-schools-do-to-children

Mawere, M. (2015). Indigenous knowledge and public education in sub-Saharan Africa. Africa Spectrum, 50(2), 57-71.

Mazrui, A. (1993). Language and the quest for liberation in Africa: The legacy of Frantz Fanon. Third World Quarterly, 14(2), 351-363.

Phelps, C., Heidl, R., \& Wadhwa, A. (2012) Knowledge, networks, and knowledge networks a review and research agenda. Journal of Management, 38(4), 1115-1166.

Reddy, V., Visser, M., Winnaar, L., Arends, F., Juan, A., Prinsloo, C. H., \& Isdale, K. (2016). TIMSS 2015: Highlights of mathematics and science achievement of Grade 9 South African learners. Pretoria, RSA: Human Sciences Research Council.

Rogoff, B. (2003) The cultural nature of human development. Oxford, UK: Oxford University Press. 
Sannino, A., \& Sutter, B. (2011) Cultural-historical activity theory and interventionist methodology: Classical legacy and contemporary developments. Theory \& Psychology, 21(5), 557-570.

Shay, M. (2016) Reimagining Indigenous education through flexi schooling. In D. Bland (Ed.), Imagination for inclusion: Diverse contexts of educational practice (pp.116127). London, UK: Routledge.

Sheppard, C. (2015) The state of youth in South Africa: Trends in education attainment. Pretoria, RSA: Human Sciences Research Council.

Shizha, E. (2013). Reclaiming our indigenous voices: The problem with postcolonial subSaharan African school curriculum, Journal of Indigenous Social Development, 2(1), $1-18$.

Song, S., Perry, L. B., \& McConney, A. (2014). Explaining the achievement gap between Indigenous and non-Indigenous students: An analysis of PISA 2009 results for Australia and New Zealand. Educational Research and Evaluation, 20(3), 178-198.

Stavenhagen, R. (2008). Building intercultural citizenship through education: A human rights approach. European Journal of Education, 43(2), 161-179.

Subreenduth, S. (2013) Theorizing social justice ambiguities in an era of neoliberalism: The case of postapartheid South Africa. Educational Theory, 63(6), 581-600.

Taylor, N. (2009). The state of South African schools Part 1: Time and the regulation of consciousness. Journal of Education, 46(10), 1-24.

Thabede, D. (2014). The African worldview as the basis of practice in the helping professions. Social Work/Maatskaplike Werk, 44(3), 233-245.

Tichy, N. M., Tushman, M. L., \& Fombrun, C. (1979). Social network analysis for organizations. Academy of management review, 4(4), 507-519.

Wartofsky, M. W. (1979). Models: Representation and the scientific understanding. Dordrecht, NL: D. Reidel. 